\title{
What determine the price of Bonga sheep at the market level in Southwestern Ethiopia? A hedonic price analysis
}

\author{
Kassa Tarekegn * (1)
}

\begin{abstract}
Background: Bonga sheep is a mutton type breed with a long-fat-tail and better body weight at maturity. The breed is especially located in the Southwestern mid and highland land areas of Ethiopia. Currently, the breed was well known in Ethiopia and also its price is higher as compared to other sheep breeds in the country. However, empirical evidence is lacking on price determinants of the breed in Ethiopia. Therefore, this research aims at identifying sheep attributes and other factors that determine the market prices of Bonga sheep in Southwestern Ethiopia.

Methodology: Data from 300 traded sheep and sheep marketers were collected from five major sheep marketing centers in the Kaffa zone. A hedonic price model adjusted for heteroscedasticity was employed to analyze the observed price data.

Results: The model result showed that the attributes of the sheep are important guiding criteria in price formulation. Among the attributes age, sex (male), colour (red), body condition (good), tail type (very fat) and absence of horn significantly and positively determine the sheep price. As well, market place (Gojebi and Bonga) near to big cities and season (holiday) and purpose of purchase are also significant determinants of bong sheep price out of the sheep attributes in Southwestern Ethiopia.

Conclusion: Targeting in systematic improvement of the significant attributes which are demanded by the market and establishment of a breeding program to make sheep improvement in a sustainable way. Besides, effort should be geared to transform the system into a market-oriented system using a value chain framework by improving access to market information.
\end{abstract}

Keywords: Bonga sheep, Attributes, Hedonic pricing, Heteroscedasticity consistent

Jel Classification: D46, M31, Q11, Q13, Q51

\section{Introduction}

Sheep are mostly kept livestock by rural smallholders as a major component of farming in Ethiopia [1]. About 31.30 million sheep populations are estimated to be found in Ethiopia [2]. In terms of breed compositions, about 99.81\% of sheep in Ethiopia are indigenous breeds [2]. Of

*Correspondence: kassatar12@gmail.com

Agricultural Economics and Gender Research Division, Southern Agricultural Research Institute, Arba Minch Agricultural Research Center (Former Bonga Center), P.O. Box 2228, Arba Minch, Ethiopia this diverse indigenous sheep breeds, at least nine breeds and 14 traditional sheep populations are distributed across diverse ecology, production systems and communities in the country [3].

There are different indigenous sheep production systems across different communities' in Ethiopia [4]. This underlines the need to characterize the breeding practices as bases for designing indigenous breed improvement strategies. For the long past, the Bonga sheep were considered as the same breed as Horro sheep. However, original author(s) and the source, provide a link to the Creative Commons licence, and indicate if changes were made. The images or other third party material in this article are included in the article's Creative Commons licence, unless indicated otherwise in a credit line to the material. If material is not included in the article's Creative Commons licence and your intended use is not permitted by statutory regulation or exceeds the permitted use, you will need to obtain permission directly from the copyright holder. To view a copy of this licence, visit http://creativecommons.org/licenses/by/4.0/. The Creative Commons Public Domain Dedication waiver (http://creativeco mmons.org/publicdomain/zero/1.0/) applies to the data made available in this article, unless otherwise stated in a credit line to the data. 
the result of breed characterization by Solomon et al. [5] indicated that there was significant genetic differentiation among the breeds. In addition, a study by Edea [6] phenotypically characterized the breeds by considering different types of traits and confirmed that the Bonga sheep are distinctly different from Horro sheep.

Currently, Bonga sheep is one of the largest breeds among indigenous breeds in Ethiopia [7]. The breed is specifically native to the Kaffa zone and is also located in southwestern mid and highland land areas of Ethiopia [8]. The sheep is the most prolific and along-fat-tail-type breed. It is also a mutton-type breed with a higher body weight at maturity [9]. Nevertheless, the production systems of Bonga sheep is semi-subsistence oriented [10]. Re-orientation of the production system, which involves designing an effective and informed breeding program, is a necessity to bring about improvements in the production system of the sector [11]. To promote marketoriented sheep production, valuation of the attributes is important for making breeding, production and efficient marketing decisions based on the market preferences for specific attributes [12].

The price of Bonga sheep for both breeding and consumption purposes is higher as compared to other breeds in Ethiopia [13]. Even though there is a large body of published literature on the identification of observed sheep price determinants in Ethiopian markets [12, 14-22], still now the reason for the high market price of Bonga sheep is not conducted. All the conducted studies revealed that the effects of animal attributes on price formulation vary across breeds and markets. This shows that targeted and rigorous studies for each sheep breed across the market and/or regions are vital.

The economic theories suggested that in a competitive market, the price of livestock is mainly determined by the animal's attributes [23, 24]. In such markets, each attribute of the animals can be evaluated by buyers when they decide to buy the animal and attach an implicit price for each attribute [25]. However, past studies by Andargachew and Brokken [15], Asresu et al. [26], Gezahegn et al. [20] and Girma et al. [27] conclude that animal markets in Ethiopia are not competitive as the characteristics of buyers may have a significant effect on prices. In such cases, in addition to animal attributes, the socio-economic characteristics of the buyer, seasons and market locations were considered as determinants of the animal price [26-29]. Therefore, unlike the case in competitive markets, the implicit prices of sheep in Ethiopian markets are a function of not only the sheep attributes but also of the individual buyer characteristics, seasons and market locations. This may be due to the lack of an open auction, classification, or grading system of livestock in Ethiopia [12]. With such market imperfections, each buyer evaluates each of the price determinants, attaches an implicit price for every determinant and decides how much she/he is willing to pay for the sheep after a long and intricate valuation process.

Like other developing countries, sheep marketing in Ethiopia was widely practiced at the village and district level markets [12]. At these levels, the price is negotiated between the sheep buyers and the producers. The producer estimates the reservation price based on level information obtained from other producers and various attributes of the animal-like age, sex, body condition. The sheep buyers guess the price of the animal based on the expected price of the animal in the intended market where the animal will be sold, transport costs, distance, various taxes and fees, personal costs involved and the profits he wants to make [7].

Most of the studies suggested that proper identification and valuation of the different attributes of the animal would make resource allocation decisions among the different livestock improvement interventions for commercialization of the system quite fast and smooth [27, 30, 31]. However, none of the previously conducted studies in Ethiopia considered the Bonga sheep breed while the breed has a high market price and increasing demand at the national level as compared to other sheep breeds in the country $[7,32]$. Therefore, this study was intended to analyze the Bonga sheep attributes considered by buyers at the market level and the association of the attributes and other socio-economic factors with the price in the Kaffa zone of southwestern Ethiopia.

\section{Research methodology}

\section{Sampling and data collections methods}

Two sampling techniques were used to select sampled sheep buyers. In the first stage, the five largest sheep markets, namely, Boka, Oda, Daka, Bonga and Gojjebi were selected purposively from Kaffa zone based on their Bonga sheep marketing channels identified by Tarekegn et al. [7]. Due to the absence of the list of sheep buyers' records in sampled markets, sampling units were not randomly chosen. Therefore, in the second stage, the convenience sampling method was applied to select 20 sheep buyers from each selected market in three rounds to capture the seasonality of sheep price. Buyers were interviewed using a pre-tested questionnaire after the purchase of sheep on a market day by a trained enumerator under the supervision of a researcher. Data on 300 traded sheep attributes and sheep buyers' characteristics were collected after sheep transactions have been carried out.

The data collection was done in three rounds at the market spots in 2018/2019. The first round of data was conducted at the end of August 2018 (Ethiopian New-year 
season) to capture the holiday season. The second round has been done at the end of January 2019 to capture the normal season since this period lacks important festivals in Ethiopian conditions at this period. The third round was undertaken in March 2019. This period corresponds to the fasting season.

\section{Analytical framework}

Different economic valuation methods were applied by researchers to understand the preference and value attributes of animals in different contexts. A brief review of different studies has shown the relevance and extensive application of the hedonic price model for the estimation of implicit prices of different attributes [12, 20, 27, 33-38]. This model has an important analytical framework in identifying attributes that determine price formulation and estimating in monetary terms [39]. The underlying assumption of the hedonic pricing model is that the attributes of a given product determine its price which means the different attributes of the product are evaluated and combined by the buyer to form a price of the product [31, $40,41]$.

The hedonic pricing model for Bonga sheep in the presence of heterogeneous buyers and markets can be given as

$$
P_{i}=F\left(Q_{i}, M_{i}, C_{i}, S_{i}, \mathrm{PP}_{i}\right),
$$

where $F$ is the function that relates sheep price $\left(P_{i}\right)$ to its attributes $\left(Q_{i}\right)$, the market in which animal is traded $\left(M_{i}\right)$, buyer's characteristics $\left(C_{i}\right)$, the season in which sheep is sold $\left(S_{i}\right)$ and the purpose of purchase $\left(\mathrm{PP}_{i}\right)$. The implicit price of an attribute, market and characteristic of buyers can be obtained by taking the partial derivative of the price function in Eq. (1). The economic theory often suggests the expected sign of the partial derivatives of price for specific attributes and characteristics but does not restrict functional form [42].

During the estimation of hedonic price function, utilization of an appropriate functional form is very critical in building an accurate and consistent econometric model $[43,44]$. Since the economic theory does not solve the problem, it is ultimately an empirical matter to choose the most suitable functional form of the hedonic price function [45]. The Box-Cox transformation approach [46] has usually been applied for this purpose. The approach nests alternative functional forms, by adding non-linear parameters, $\theta$ and $\lambda$ on the dependent and independent variables, respectively. It can be expressed as

$$
P=\left\{\begin{array}{cc}
\frac{P^{\theta}-1}{\theta} & \text { if } \theta \neq 0 \\
\operatorname{Ln} \theta & \text { if } \theta=0
\end{array}, Z_{i}=\left\{\begin{array}{cc}
\frac{P^{\lambda}-1}{\ln ^{\lambda}} & \text { if } \lambda \neq 0 \\
\operatorname{Ln} \lambda & \text { if } \lambda=0
\end{array}\right.\right.
$$

The Box-Cox transformation provides four possible functional outcomes: i. Linear, when $\theta=\lambda=1$;

ii. Double-logarithmic, $\theta=\lambda=0$;

iii. Semi-logarithmic, when $\theta=0$ and $\lambda=1$; and

iv. Liner-logarithmic, $\theta=1$ and $\lambda=1$.

However, individual and joint tests of the Box-Cox parameters may lead to un-conclusive results. According to Ballco and de-Magistris [47], Ballco and Gracia [45] and Cabrera et al. [48], the Vuong test may be applied to select the functional form that best fits the data. The Vuong test is based on a comparison of the predicted probabilities of two models [49]. Thus, choosing the best values in terms of log-likelihood and the variance estimate of their difference is recommended. Accordingly, the likelihood ratio for each functional form $i$ is expressed as

$$
\mathrm{LR}^{i}=\left(\lambda_{l} \theta_{l}, \lambda_{m} \theta_{m}\right)=l l_{l}^{i}-l l_{m}^{i}
$$

where $l, m$ are one of any of the four models $(m)$ defined by the Box-Cox transformation and $l l_{m}$ is the log-likelihood function for observation $i$ evaluated at the parameter estimates of the model $m$. The Vuong test is then given by

$$
\text { Vuong }=\frac{\sqrt{n}\left[\frac{1}{n} \sum_{i=1}^{n} \mathrm{LR}_{i}\right]}{\sqrt{\frac{1}{n} \sum_{i=1}^{n}\left(\mathrm{LR}_{i}-\overline{\mathrm{LR}_{i}}\right)^{2}}}
$$

where $n$ is the number of observations, $\mathrm{LR}_{i}$ is the likelihood ratio between the models $j$ and $k\left(\mathrm{LR}_{i}=l l_{j}-l l_{k}\right)$, and $\overline{\mathrm{LR}_{i}}$ is the mean with a normal distribution. Therefore, values larger than the critical $N_{\alpha / 2}$ ratify model $j$ and values smaller than $-N_{\alpha / 2}$ favor model $k$; while other values indicate insignificant differences between the two models.

\section{Econometric model specifications}

According to Box-Cox test and Vuong test in Tables 3 and 4, this study used the log-linear functional form. The functional form of the model is specified as follows:

$$
\ln (p)=X \beta+\varepsilon
$$

where $X$ is the vector of independent variables including sheep attributes, market place and seasonally and socioeconomic characteristics of buyers; $\beta$ is a vector of parameters to be estimated, $\varepsilon$ is an independent and identically distributed error term and $p$ is the price per sheep.

The check reliability of the estimates, test for specification error or omitted variable, multicollinearity, heteroscedasticity and normality assumption of error terms were applied. The Ramsey test was used to capture 
specification error or omitted variable problems that violating the ordinary least squares (OLS) assumptions and making our OLS estimates biased and inconsistent [50]. Whereas the Variance Inflation Factor (VIF) technique was employed to detect the presence of multicollinearity among the variables which results in unstable OLS estimates, larger standard errors of the estimates, and wider confidence intervals $[51,52]$. The heteroskedasticity problem that exists when the variances of error terms are not constant was detected using the Breusch Pagan test [53]. Finally, to test the normality assumption, Shapiro-Wilk's $W$ test is recommended for medium samples of up to $n=2000$ [54]. From this, our sample $(n=300)$ is too small to give robust test results. Alternatively, a very simple method of checking the normality assumption is to construct a normal probability plot of the residuals $[54,55]$. Thus, to test the normality assumption residuals, a visual inspection of error terms distribution by normal probability plot was used.

In the presence of heteroscedasticity, the OLS estimator of the vector of regression parameters is no longer efficient in the class of linear and unbiased estimators, but it remains unbiased, consistent and asymptotically normal [56]. Hence, the usual tests of significance are generally inappropriate and their use can lead to incorrect inference [57]. This requires the use of a robust estimation procedure through the derivation of an alternative estimator that is efficient. Alternatively, OLS can be used with adjusted standard errors (SEs) that are consistent but not efficient [58].

Of the alternatives ways of corrections, White's [53] formula was generally used in the empirical literature to obtain heteroscedastic-consistent standard errors [59]. However, simulation-based results indicate that it is a bit too small matrix and a bit too optimistic white estimator resulting in larger asymptotic $t$-ratios [50]. To overcome the issues, MacKinnon and White [60] employed the heteroscedastic-consistent covariance matrix (HCCM) estimators, such as $\mathrm{HC}, \mathrm{HC} 1, \mathrm{HC} 2$ and $\mathrm{HC} 3$ that provide a consistent estimator of the covariance matrix. Lately, Davidson and MacKinnon [61] suggest three ( $\mathrm{HCO}, \mathrm{HC} 2$, and HC3) alternative ways of corrections. The alternative covariance matrix estimators of the error term, including the OLS and that of White [53], are specified as

$$
\begin{aligned}
& \mathrm{OLS}=\frac{\sum e_{i}^{2}}{n-k}\left(X^{\prime} X\right)^{-1} \\
& \mathrm{HCO}=\left(X^{\prime} X\right)^{-1} X^{\prime} \operatorname{diag}\left[e_{i}^{2}\right] X\left(X^{\prime} X\right)^{-1} \\
& \mathrm{HC} 1=\frac{n}{n-k}\left(X^{\prime} X\right)^{-1} X^{\prime} \operatorname{diag}\left[e_{i}^{2}\right] X\left(X^{\prime} X\right)^{-1}
\end{aligned}
$$

$$
\begin{aligned}
& \mathrm{HC} 2=\left(X^{\prime} X\right)^{-1} X^{\prime} \operatorname{diag}\left[\frac{e_{i}^{2}}{1-h_{i i}}\right] X\left(X^{\prime} X\right)^{-1} \\
& \mathrm{HC} 3=\left(X^{\prime} X\right)^{-1} X^{\prime} \operatorname{diag}\left[\frac{e_{i}^{2}}{\left(1-h_{i i}\right)^{2}}\right] X\left(X^{\prime} X\right)^{-1} .
\end{aligned}
$$

The conditional distribution of the errors given the matrix of explanatory variables has zero mean $[E(\varepsilon)=0]$, constant variance $[V(\varepsilon)=\sigma 2]$ and zero covariance $[E(\varepsilon X)=0]$.

The difference among these alternative covariance matrix estimators lies in the SEs where the one with the largest SE is more robust [61]. As well, Long and Ervin [57] suggested that the least square residuals from $\mathrm{HCO}$ and $\mathrm{HC} 1$ tend to be very small implying that the estimates from $\mathrm{HC} 0$ and $\mathrm{HC} 1$ become less robust. While, $\mathrm{HC} 2$ and $\mathrm{HC} 3$ are the best possible covariance matrix estimators, the superiority of one over the other lies in its properties when testing coefficients that are most strongly affected by heteroscedasticity [56]. As a result, this study adopted both the $\mathrm{HC} 2$ and $\mathrm{HC} 3$ estimators. The efficiency differences between $\mathrm{HC} 2$ and $\mathrm{HC} 3$ estimators are based on the SEs of coefficients. The HC2 SEs for all coefficients were found to be lower than those for HC3 [12, 33, 59]. The lower SE is inflated the $t$ values possibly leading to erroneous rejections of the null hypothesis. As a result, making inferences from $\mathrm{HC} 2$ is unreliable and shows that HC3 outperforms HC2 [59]. Therefore, in this study, the HC3 estimation results were used for inferences.

\section{The hypothesis of the variables}

It is generally hypothesized that the values of the commodities attributes contribute to the price of the commodities [15]. Therefore, a composite of the implicit prices of the product's attributes is reflected within the observed price of a product. An implicit price of a product during a competitive market is going to be a function of the commodities attributes alone. This suggests that only products are differentiated, while their markets, buyers and sellers are not [24]. However, most of the previous research exploring the determinants of animals' price suggested that the attribute of animals, marketing characteristics, market place and seasons are the most determinants in developing countries where the animal market is not competitive including Ethiopia. As an example, the study investigated by Afzal et al. [62]; Ahmad et al. [33]; Asresu et al. [26]; Gezahegn et al. [20]; Jabbar [35]; Naanep et al. [63]; Zelalem et al. [12] confirms that animals' physical attributes and other socio-economic factors, such as a market place, season, buyers characteristics were variably important in explaining variation in price among animals. In the case 
of exploring the determinants of Bonga sheep's price at the market level, the most task was to explore which factors potentially influence and the way these factors are associated with the variable. Thus based on the findings of earlier empirical evidence, the hypothesized explanatory variables that determine the price of Bonga sheep are explained in Table 1.

\section{Results and discussion}

\section{Descriptive statistics results}

The price of Bonga sheep was set by visual inspection of the animals due to a lack of weight-based marketing for animals in the country. This could be done by considering different sheep attributes, seasonality and market location. This type of marketing was quite subjective and hence favorable to middlemen at the expense of producers [21]. The descriptive result (Table 2) shows that the average price of the sheep marketed was 2750 ETB with a standard deviation of 596. From the selected five markets, the large proportions of sheep were marketed at Bong and Gojjeb market places. This may be due to the proximity of the markets to Jimma and Shebe towns where a large number of sheep traders and buyers are available. As indicated in Table 2, a large proportion of sheep (52.00\%) was bought for reselling purposes. While the remaining $21.00 \%, 17.33 \%$ and $9.67 \%$ were purchased for rearing, slaughtering consumption and religious purposes, respectively. Among the buyers of sheep, a larger proportion of sheep transactions was carried out by traders (42.67\%), while the remaining $35.00 \%$ and $22.33 \%$ were by producers and butchers/restaurants, respectively.

Regarding attributes of the sheep, a large proportion (46.00\%) of the sampled sheep buyers prefer average body conditions (Table 2). Concerning the colour, the most preferred ones in the study area were red and brown. Occasionally some buyers prefer a particular colour while buying an animal because of cultural reasons. The largest proportion of respondents $(46.00 \%)$ prefer the fat-tailed sheep among the others (Table 2). Regarding the sex of sheep sold, $78.00 \%$ of sampled prefers male sheep. The average age of marketed sheep was 13.34 months that is obtained by the arrangement of teeth. Concerning the seasonality of sheep marketing, a large number of animals were traded around the festival seasons. As expected, the highest proportions (53.00\%) of the sampled respondents confirm that holiday seasons such as Christian and Muslim festivals are the main market price determinants.

Besides, the price of sheep varies across months in the year (Fig. 1). The result also shows that the highest price was recorded in September, December, April and August. This may be because these months are mostly holiday months in Ethiopia condition.

\section{Econometric results}

The first step in the hedonic price approach started with the estimation of the Box-Cox price regression (Eq. 2) using STATA 16.0. While the second step estimated the testing of the possible equation specifications. The test results shown in Table 3 indicated that the two possible functional forms were not rejected.

Since Box-Cox parameters tests do not give direction to select the best functional form finally, the Vuong test [49] was applied to select the functional form that best fits the data. The results of the Vuong test in Table 4 indicate that the semi-logarithmic (log-lin) functional form is suitable. Likewise, additional statistical parameters have been performed to verify the functional form that best fits the model $[45,47,48,64,65]$. According to likelihood ratio statistics, the log-lin semi-logarithmic functional form was significantly preferred to a lin-log semi-logarithmic and a double-logarithmic (log-log) specification.

Table 1 Description of variables used in the estimation of the hedonic price function

\begin{tabular}{|c|c|}
\hline Attributes & Attribute description and measurement \\
\hline Sheep price & Price of sheep per head by Ethiopian Birr (ETB) in natural logarithm \\
\hline Age of sheep & Continuous; measured by the arrangement of teeth in months \\
\hline Sex of sheep & Dummy; $1=$ male, $0=$ female \\
\hline Coat colour & Categorical; $1=$ red, $2=$ white-mixed, $3=$ brown, $4=$ black \\
\hline Body condition & Categorical; $1=$ good, $2=$ average, $3=$ poor \\
\hline Tail type & Categorical; $1=$ very fat, $2=$ fat tailed, $3=$ thin tailed \\
\hline Horn type & Dummy; $1=$ horny, $0=$ hornless \\
\hline Buyer type & Categorical; $1=$ farmer $2=$ consumer $3=$ trader $4=$ Butchers and hotels \\
\hline Market place & Categorical; $1=$ boka, $2=$ bonga, $3=$ gojjeb, $4=$ daka, $5=$ Oda \\
\hline Seasons of sheep sold & Categorical; $1=$ holiday seasons, $2=$ fasting seasons, $3=$ normal season \\
\hline Purpose of purchase & $\begin{array}{l}\text { Categorical; } 1=\text { resale, } 2=\text { rearing, } 3=\text { slaughtering(consumption), } \\
4=\text { Religious purpose }\end{array}$ \\
\hline
\end{tabular}


Table 2 Descriptive statistics of variables used in the model. Source, Author computation, Study Data, 2019

\begin{tabular}{|c|c|c|c|}
\hline Continuous variables & Observation & Mean & St.dev \\
\hline Price of sheep in Ethiopian Birr (ETB) & 300 & 2750.96 & 596.07 \\
\hline Age of sheep in months & 300 & 13.34 & 5.15 \\
\hline Categorical/dummy variables & Responses & Frequency & Percentage \\
\hline \multirow[t]{4}{*}{ Purpose of purchase } & Reselling & 156 & 52.00 \\
\hline & Rearing & 63 & 21.00 \\
\hline & Slaughtering (consumption) & 52 & 17.33 \\
\hline & Religious purpose & 29 & 9.67 \\
\hline \multirow[t]{5}{*}{ Market place } & Boka & 83 & 27.67 \\
\hline & Bonga & 52 & 17.33 \\
\hline & Gojebi & 58 & 19.33 \\
\hline & Daka & 67 & 22.33 \\
\hline & Oda & 40 & 13.33 \\
\hline \multirow[t]{4}{*}{ Buyer type } & Farmer & 67 & 22.33 \\
\hline & Traders & 128 & 42.67 \\
\hline & Butchers/hotel & 64 & 21.33 \\
\hline & Individual consumers & 41 & 13.67 \\
\hline \multirow[t]{2}{*}{ Sex of sheep } & Male & 233 & 77.67 \\
\hline & Female & 66 & 22.00 \\
\hline \multirow[t]{3}{*}{ Season } & Fasting season & 53 & 17.67 \\
\hline & Holidays season & 159 & 53.00 \\
\hline & Normal time & 88 & 29.33 \\
\hline \multirow[t]{3}{*}{ Body condition } & Poor & 81 & 27.00 \\
\hline & Average & 139 & 46.33 \\
\hline & Good & 80 & 26.67 \\
\hline \multirow[t]{4}{*}{ Colour } & Red & 119 & 39.67 \\
\hline & Brown & 124 & 41.33 \\
\hline & White-mixed & 37 & 12.33 \\
\hline & Others (black) & 20 & 6.67 \\
\hline \multirow[t]{3}{*}{ Tail type } & Very fat-tailed & 66 & 22.00 \\
\hline & Fat-tailed & 139 & 46.33 \\
\hline & Thin tailed & 95 & 31.67 \\
\hline \multirow[t]{2}{*}{ Sex of sheep } & Male & 233 & 77.66 \\
\hline & Female & 66 & 22.00 \\
\hline \multirow[t]{2}{*}{ Horn type } & Horney & 37 & 12.33 \\
\hline & Hornless & 263 & 87.67 \\
\hline
\end{tabular}

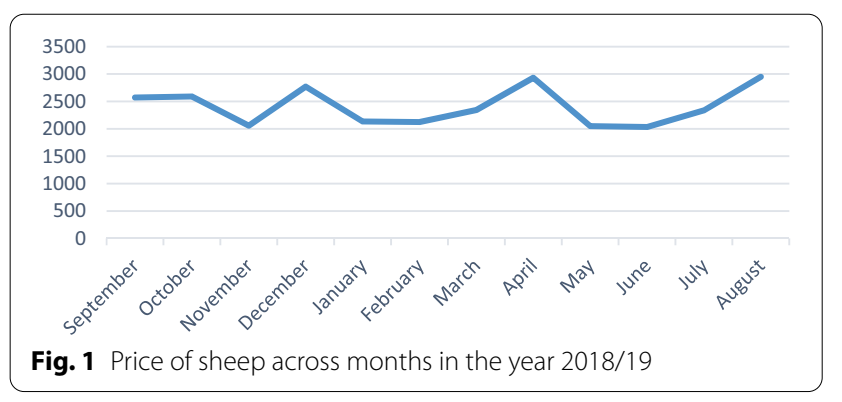

Table 3 Box-Cox transformation

\begin{tabular}{lllcl}
\hline Functional form & $\boldsymbol{\theta}$ value & $\boldsymbol{\lambda}$ value & $\begin{array}{c}\text { LR-statistic } \\
\mathbf{c h i}^{\mathbf{2}}(\boldsymbol{p} \text { value) }\end{array}$ & Result \\
\hline Log-lin & 0 & 1 & $0.13(0.86)$ & Not reject \\
Lin-log & 1 & 0 & $61.05(0.03)$ & Reject \\
Lin-lin & 1 & 1 & $31.41(0.01)$ & Reject \\
Log-log & 0 & 0 & $1.79(0.66)$ & Not reject \\
\hline
\end{tabular}


Table 4 Vuong's test results

\begin{tabular}{lcl}
\hline Ho & Vuong statistic & Accepted form \\
\hline Log-lin vs. lin-log & $-12.765^{\mathrm{a}}$ & Log-lin \\
Log-lin vs. lin-lin & 0.025 & - \\
Log-lin vs. log-log & -0.056 & - \\
Lin-log vs. lin-lin & 0.0046 & - \\
Lin-log vs. log-log & 0.073 & - \\
Lin-lin vs. log-log & 0.028 & -
\end{tabular}

${ }^{a}$ The values were higher or lower than the critical values of 1.96 and -1.96 , respectively, rejecting the null hypothesis of no-differences among functional forms

In addition, the adopted functional form was superior to a lin-log semi-logarithmic or a double-logarithmic (log-log) since the goodness-of-fit $R^{2}=0.81$ were higher and significant $(F$-statistic $<0.000)$ while the Akaike and Schwarz information criterion was lower than those of the lin-log and log-log model. Besides, the normality of residuals test for log-lin functional form by normal probability plot (Appendix Fig. 2) shows that there are no problems with the issues since the normal probability plot for residuals approaches to normality line.

Among the post estimation tests, the test result from variance inflation factor (VIF) for multicollinearity shows that there is no serious collinearity between the independent variables since the mean VIF value (2.25) was less than five [52]. In addition, the result from the Ramsey test for a model specification shows that the model has no omitted variables problem since $F(3,274)$ value of 0.98; prob $>F=0.4049$; implying non-rejection of the null hypothesis. Similarly, the Breusch Pagan and White test for the heteroscedasticity shows that the null hypothesis for the homoscedasticity in the error term was rejected $\left(\chi^{2}(1)=20.47\right.$; prob $\left.>\chi^{2}=0.0000\right)$. Hence, to correct the issue the alternative ways of heteroscedasticity consistent standard errors ( $\mathrm{HC} 0, \mathrm{HC} 2$ and HC3) were applied [53]. According to Long and Ervin [57], HC3 is a superior test for coefficients that are most affected by heteroscedasticity among the alternatives. Therefore, this study considered HC3 for testing coefficients of the hedonic model.

The goodness of fit of the estimated model with $R^{2}$ was 0.81 that passed the tests and indicating about $81 \%$ of the variation in the price of sheep at the market level was explained by the variables included in this model. HC3 estimation result in the fourth column of Table 5 indicates that body condition, coat colour, age, tail type, horn type, season, market location and the purpose of bought are statistically significant determinants of sheep prices in the rural markets of the Kaffa zone.
Taking into account the log-linear functional form of the equation, the coefficient of independent variables can be interpreted in terms of percentage for the sheep price to unit change for continuous variables while base comparison for dummy explanatory variables. Values appearing in the last column of Table 5 were the result of applying the percentage impact on a reference price. In this case, the average price of the sample is 2750.96 ETB/head of sheep, so implicit prices were calculated.

The body conditions of sheep (in terms of meat, fat and height) significantly affects sheep prices among all sampled markets. As evident from the HC3 regression result, a sheep with good and average body condition has received $16.70 \%$ and $10.40 \%$ higher prices as compared to sheep with poor body conditions, respectively (Table 5). In particular, sheep buyers pay an additional price of 285 and 458ETB per head for sheep with average and good body conditions, respectively (Table 5 ). This indicates that the price of Bonga sheep increases with better meat and fat size as well as height. This result agrees with the findings of Beneberu [66], Zelalem et al. [12] and Zewdie and Teferi [67].

The coat colour of a sheep is also one of the statistically significant attributes considered by buyers during purchasing. The econometric estimations result show that among the considered coat colours, brown and black coat colours negatively and significantly determine the price of the Bonga sheep as compared to red. More specifically, as compared to red coat colour, the price of sheep decreased by $12.60 \%$ and $6.50 \%$ for black and brown coloured sheep with a price discount of $345.50 \mathrm{ETB} / \mathrm{sheep}$ and $178.50 \mathrm{ETB} / \mathrm{sheep}$, respectively. The black colour exhibits the lowest value among the colours included in the model. This may be due to society's perception of colour as a sign of sadness. The study by Metsafe et al. [8] confirms that black coloured sheep are considered as a sign of bad colour in the Kaffa community which affects the price of sheep during selection and marketing of the sheep. This result is also consistent with the finding of Zelalem et al. [12].

The sex of sheep is another attribute that significantly affects the price of sheep at the market level. The regression result shows that the price of female sheep is significantly lower by $16.00 \%$ in all markets than the price for male sheep with a price discount of $440 \mathrm{ETB} /$ sheep (Table 5). This may be due to societies' consumption preference of male as compared to female sheep. The study by Gezahegn et al. [20] also confirms that people generally prefer to buy males than females for consumption purposes in Ethiopia. Jabo and Adamu [68] also reported that prices of male animals were significantly higher than female animals in the Kaduna State of Nigeria but a study by Nadhem et al. [30] in Kenya contradicted the idea. 
Table 5 Results of the OLS and heteroscedastic consistent $(\mathrm{HCO}, \mathrm{HC} 3, \mathrm{HC} 3)$ hedonic models

\begin{tabular}{|c|c|c|c|c|c|}
\hline Explanatory variables & Coef. (OLS Std. Err) & Coef. (HCO Std. Err) & Coef. (HC2 Std. Err) & Coef. (HC3 Std. Err) & IP (ETB/head) \\
\hline \multicolumn{6}{|c|}{ Market place (boka as a base category) } \\
\hline Bonga & $0.0977^{* * *}(0.0226)$ & $0.0977^{* * *}(0.0227)$ & $0.0977^{* * *}(0.0225)$ & $0.0977^{* * *}(0.0229)$ & 268.77 \\
\hline Gojjeb & $0.1149^{* * *}(0.0257)$ & $0.1149^{* * *}(0.0259)$ & $0.1149^{* * *}(0.0259)$ & $0.1149^{* * *}(0.0262)$ & 316.10 \\
\hline Daka & $-0.0365 *(0.0208)$ & $-0.0365^{*}(0.0209)$ & $-0.0365^{*}(0.0207)$ & $-0.0365^{*}(0.0209)$ & -100.40 \\
\hline Oda & $-0.0070(0.0305)$ & $-0.0070(0.0308)$ & $-0.0070(0.0309)$ & $-0.007(0.0310)$ & -19.25 \\
\hline \multicolumn{6}{|c|}{ Sex of sheep sold (male as a base category) } \\
\hline Female & $-0.1600^{* * *}(0.0165)$ & $\left.-0.1600^{* * *}(0.0165)\right)$ & $-0.1600^{* * *}(0.0167)$ & $-0.1600^{* * *}(0.0167)$ & -440.15 \\
\hline Age & $0.0341^{* * *}(0.0077)$ & $0.0341^{* * *}(0.0079)$ & $0.0341^{* * *}(0.0079)$ & $0.0341^{* * *}(0.0079)$ & 93.86 \\
\hline \multicolumn{6}{|c|}{ Body condition (poor as a base category) } \\
\hline Average & $0.1038^{* * *}(0.0169)$ & $0.1038^{* * *}(0.0169)$ & $0.1038^{* * *}(0.0170)$ & $0.1038^{* * *}(0.0178)$ & 285.55 \\
\hline Good & $0.1667^{* * *}(0.0241)$ & $0.1667^{* * *}(0.0243)$ & $0.1667^{* * *}(0.0245)$ & $0.1667^{* * *}(0.0251)$ & 458.59 \\
\hline \multicolumn{6}{|c|}{ Coat colour (red as a base category) } \\
\hline White-mixed & $-0.0192(0.0148)$ & $-0.0192(0.0149)$ & $-0.0192(0.0152)$ & $-0.0192(0.0155)$ & -52.82 \\
\hline Brown & $-0.0649 *(0.0347)$ & $-0.0649^{*}(0.0349)$ & $-0.0649 *(0.0349)$ & $-0.0649 *(0.0353)$ & -178.54 \\
\hline Others (black) & $-0.1256^{* * *}(0.0113)$ & $-0.1256^{* * *}(0.0115)$ & $-0.1256^{* * *}(0.0117)$ & $-0.1256^{* * *}(0.0121)$ & -345.52 \\
\hline \multicolumn{6}{|c|}{ Tail type of the sheep (Very fat as a basecategory) } \\
\hline Fat tailed & $-0.0570^{* * *}(0.0209)$ & $-0.0570^{* * *}(0.0212)$ & $-0.0570^{* * *}(0.0224)$ & $-0.0570^{* * *}(0.0227)$ & -156.83 \\
\hline Thin tailed & $-0.0954^{* * *}(0.0325)$ & $-0.0954^{* * *}(0.0325)$ & $-0.0954^{* * *}(0.0328)$ & $-0.0954^{* * *}(0.0331)$ & -262.44 \\
\hline \multicolumn{6}{|c|}{ Horn type (horny as a base category) } \\
\hline Hornless & $0.0899 * * *(0.0242)$ & $0.0899^{* * *}(0.0238)$ & $0.0899 * * *(0.0245)$ & $0.0899 * * *(0.0251)$ & 247.31 \\
\hline \multicolumn{6}{|c|}{ Purpose of purchase (rearing as a base category) } \\
\hline Resale & $0.0874(0.0732)$ & $0.0874(0.0736)$ & $0.0874(0.0736)$ & $0.0874(0.0739)$ & 240.44 \\
\hline Slaughtering (consumption) & $0.0963^{* * *}(0.0412)$ & $0.0963^{* * *}(0.0415)$ & $0.0963^{* * *}(0.0418)$ & $0.0963^{* * *}(0.0424)$ & 264.92 \\
\hline Religious purpose & $0.1161^{* * *}(0.0269)$ & $0.1161^{* * *}(0.0271)$ & $0.1161^{* * *}(0.0272)$ & $0.1161^{* * *}(0.0275)$ & 319.38 \\
\hline \multicolumn{6}{|c|}{ Buyer type (farmers as a base category) } \\
\hline Traders & $0.0106(0.0252)$ & $0.0106(0.0234)$ & $0.0106(0.0234)$ & $0.0106(0.0244)$ & 29.16 \\
\hline Butcher/hotel/restaurants & $0.0237(0.02468)$ & $0.0237(0.02471)$ & $0.0237(0.02469)$ & $0.0237(0.02473)$ & 65.19 \\
\hline Individual consumer & $0.0756(0.0745)$ & $0.0756(0.0743)$ & $0.0756(0.0743)$ & $0.0756(0.0749)$ & 207.97 \\
\hline \multicolumn{6}{|c|}{ Season of sheep sold (fasting season as a base category) } \\
\hline Holidays season & $0.1897^{* * *}(0.0239)$ & $0.1897^{* * *}(0.0243)$ & $0.1897^{* * *}(0.0246)$ & $0.1897^{* * *}(0.0249)$ & 521.86 \\
\hline Normal time & $0.0231(0.0300)$ & $0.0231(0.0308)$ & $0.0231(0.0313)$ & $0.0231(0.0412)$ & 63.55 \\
\hline Constant & $1.6351^{* * *}(0.0763)$ & $1.6351^{* * *}(0.0769)$ & $1.6351^{* * *}(0.0764)$ & $1.6351^{* * *}(0.0773)$ & - \\
\hline \multicolumn{6}{|c|}{ Observations $=300 ; F(22,277)=52.60 ;$ Prob $>F=0.0000, R$-squared $=0.8069$, Adjusted $R$-squared $=0.7915$} \\
\hline
\end{tabular}

Coef: coefficient; Standard errors in parentheses; IP: implicit price; Average price of the sample: $2750.96 \mathrm{ETB} / \mathrm{head}$

$* * * * *$, Significant at $1 \%, 5 \%$ and $10 \%$ level, respectively

The regression result also confirmed that the age of sheep affects the price of the sheep significantly and positively. The type and number of teeth broken out were used to measure the age of sheep by months [8]. The regression result shows the sheep receive a premium price of $3.40 \%$ per sheep as the age of sheep increases by 1 month. In another saying additional 99ETB/sheep will be paid for each additional age increment by the month. A study by Feven [18] and Ahmad et al. [13] in Ethiopia found a similar result that confirms a positive relationship between age and the price of animals sold.

Concerning the tail type of sheep, sheep with very fattailed receives a price premium of about $5.7 \%$ and $9.5 \%$ over fat and tin-tailed sheep with a price premium of 157 and $262 \mathrm{ETB} /$ sheep, respectively (Table 5 ). This may be the most of the Ethiopian consumer preference of fat on the very fat tail. Gezahegn et al. [20] also find similar results.

Besides, the type of horn is a significant determinant of sheep prices in the study area. According to the result in Table 5, the hornless sheep have a price premium of about $9.00 \%$ over horny ones with a price premium of $247 \mathrm{ETB} /$ sheep. This may be that the horny sheep in the study area was mostly not preferred due to low demand in the market. As a result, the buyers are not willing to pay higher prices as compared to hornless sheep. However, a study 
by Asresu et al. [26] indicated that goats with horns have a price premium over goats that are not horned.

Out of sheep attributes, the results from the regressed hedonic model revealed that sheep price was positively affected by market place (Bonga and Gojjeb). For instance, sheep sold in Bonga and Gojjeb received higher prices of $9.77 \%$ and $11.50 \%$ with additional implicit prices of 289 and 316ETB/head, respectively. While sheep sold in Daka had received a significantly lower price $(3.65 \%)$ with an implicit price of $-100 \mathrm{ETB} /$ head. The parameter estimates for market locations in the model imply spatial price variability in the study area. This price variation among markets may be due to the proximity of the Gojjeb market to Jimma town (a big city in Southwestern Ethiopia). While the Daka market affects the sheep price negatively as compared to Boka by decreasing the price paid for sheep purchased by 3.65\% may be due to the remoteness of the Daka market. Srinivasan et al. [39] and Ahmad et al. [33] also found that animal prices vary significantly among markets.

The purpose of the sheep purchased is the significant variable affecting sheep prices in Ethiopia. It was considered here as a proxy variable to capture the bargaining power of buyers. From the regression result, among the purposes of sheep purchase, the price of sheep purchased for slaughtering and religious purposes get $9.60 \%$ and $11.60 \%$ significantly higher price premium with an additional price premium of 265 and 319ETB/sheep over the price of sheep purchased for rearing purposes, respectively (Table 5). This may be due to the buyers' role in price formation. For instance, those who buy for slaughtering at-home/hotel/butchering house and religious purpose target to optimize their satisfaction. Farmers may prefer to purchase small animals at lower prices animals for rearing (breeding and fattening). They bought sheep for stock replacement and flock re-establishment at a price discount over consumers and mostly purchase female sheep at or below the first lamb delivery age. A similar result was found by Feven [18]. Traders bought sheep at a discount price over consumers. Unlike traders, butchers/restaurants often bought big sheep aiming a profit-making through value addition at a price premium over consumers.

Finally, the season in which the animal is sold is another most important factor that determines the price of sheep in the study area. The holiday occasions of Ethiopia especially Christmas, Easter and New Year are the main seasons where sheep are highly purchased. The regression result confirms that sheep purchased on holiday seasons for consumption and resale received a premium of $18.90 \%$ as compared to the fasting seasons with a premium price of $522 \mathrm{ETB} / \mathrm{sheep}$. This may be because of the seasonal nature of the consumption habit for Ethiopian society preference of sheep mutton during the holiday than normal season. The descriptive result in Fig. 1 also confirms that the price of the sheep during Ethiopian holiday months (December, April, August and September) as compared to other months. Andargachew and Brokken [15], Gezahegn et al. [20], Teklwolde et al. [22] also reported that animal prices were significantly higher during holiday seasons as compared to other periods.

\section{Conclusion}

This study finds a direct relationship between the different attributes (sheep attributes, buyers' objectives, market locations and seasons of sale) and the premium prices. The most determining factors of the sheep price, age, colour, tail type, sex, horn type and body conditions were significant sheep attributes. Within given attributes, red coat colour, very fat-tailed sheep and hornless sheep needs received the highest price premium as compared to their counterpart. Thus, the research institutions and livestock offices/departments should focus on the improvement of these attributes that affect mostly the price of sheep at the market level. In addition, sheep with good body conditions got an additional premium price as compared to sheep with poor body conditions. As a result, sheep producers and other concerned bodies should target the improvement of sheep body condition by application of proper sheep production technologies, selection of appropriate breeding rams, increasing the availability of feeds and feeding practice adjustment.

The heterogeneity in buyers' objectives and sheep marketing places also have a significant effect on sheep price formulation in the study area. Thus, targeting a place of sale to gain more from existing market opportunities is required. This inadequate information about prices results in poor integration of spatially dispersed markets and high margins for the intermediaries [14]. Thus, the trade and market deployment departments from the government side should also work on improving market information for sheep producers. Finally, the importance of season in determining the price paid for sheep is confirmed as well justifies the need for targeting season so that smallholder sheep keepers to improve their returns. Besides, this study only focuses on attributes of sheep and some other market participants' characteristics by considering other price determinants constants. Thus, the animal breeders and other animal production researchers should focus on the improvement of the identified sheep attributes in their future researches.

\section{Appendix}

See Fig. 2. 


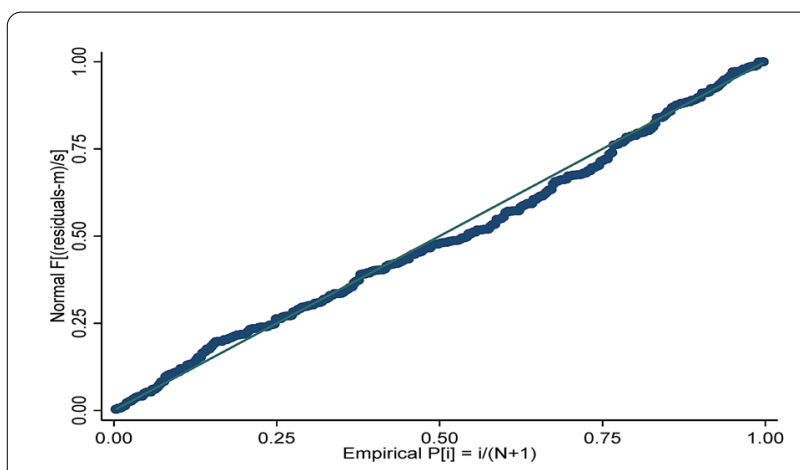

Fig. 2 Normal probability plot to test the normal distribution of error terms

\section{Abbreviations}

BARC: Bonga Agricultural Research Center; CSA: Central statistical agency of Ethiopia; HC: Heteroscedastic-consistent; MOA: Ministry of Agriculture; SNNPR: Southern Nation Nationality Peoples' Region; OLS: Ordinary least squares; SAR: Southern Agricultural Research Institute; VIF: Variance inflation factor.

\section{Acknowledgements}

The author would like to gratefully thank Southern Agricultural Research Institute (SARI) for its financial support. The sampled respondents were also acknowledged for providing their valuable information. Finally, the author wishes to express his appreciation to the Bonga Agricultural Research Center (BARC) for its logistic support.

\section{Authors' contributions}

KT contributed to research proposal writing, data collection, data analysis, data interpretation and article writing. The author read and approved the final manuscript.

\section{Authors' information}

Kassa Tarekegn is Researcher-l, Agricultural Economics Research at Arba Minch Agricultural Research Center (former Bonga Center), Southern Agricultural Research Institute (SARI), Ethiopia.

\section{Funding}

Southern Agricultural Research Institute (SARI), Ethiopia.

\section{Availability of data and materials}

The data sets are used and/or analyzed during the current study available from the corresponding author on request.

\section{Declarations}

\section{Ethics approval and consent to participate}

Not applicable.

\section{Consent for publication}

Not applicable.

\section{Competing interests}

I declare that the author does not have any competing interests.

Received: 30 March 2021 Accepted: 24 August 2021

Published online: 27 December 2021

\section{References}

1. Aynalem H, Solomon G, Tesfaye G, Joaquín PM, Peter A, Mourad R, Barbara R. Community-based breeding programs are a viable solution for
Ethiopian small ruminant genetic improvement but require public and private investments. J Anim Breed Genet. 2019;136(5):319-28.

2. CSA (Central Statistics Agency). Agricultural sample survey. Report on livestock and livestock characteristics. Statistical Bulletin, 587, Addis Ababa, Ethiopia. 2018;2.

3. Gebremariam B. Review work on breeding objectives and practices of small holder sheep production in Ethiopia. J Vet Sci Anim Husb. 2019;7(1):1-7.

4. Gizaw S, Getachew T, Edea Z, Mirkena T, Duguma G et al. Characterization of indigenous breeding strategies of the sheep farming communities of Ethiopia: A basis for designing community-based breeding programs. ICARDA working paper, Aleppo, Syria. 2013; p. 47.

5. Solomon G, Van Arendonk J, Komen H, et al. Population structure, genetic variation, and morphological diversity in indigenous sheep of Ethiopia. Anim Genet. 2007;38:621-8.

6. Edea Z. Characterization of Bonga and Horro Indigenous Sheep breeds of smallholders for designing community-based breeding strategies in Ethiopia. MSc thesis, submitted to the School of Graduate Studies of Haramaya Univ, Dire Dawa, Ethiopia. 2008.

7. Tarekegn K, Abate Z, Gizaw H. Analysis of sheep value chain in Kafa Zone, southern Ethiopia. Int Sci Footpr. 2016;4(2):12-23.

8. Metsafe M, Sandip B, Aynalem H. Selection practices of Bonga sheep reared in southern Ethiopia. Proc Zool Soc. 2017;71(2):164-9. https:// doi.org/10.1007/s12595-017-0207-1.

9. Abate Z. Performance evaluation of Bonga rams and their progenies in different agro-ecologies of southern Ethiopia. MSc thesis, Jimma University, Jimma, Ethiopia. 2018.

10. Metsafe M, Sandip B, Aynalem H. Sheep production and breeding practice in Adyio Kaka district of Kafa zone, southern Ethiopia. J Biol Agric Healthc. 2017;7(3):16-20.

11. Scarpa R, Kristjanson P, Ruto E, Radeny M, Rege JEO. Valuing indigenous cattle breed in Kenya: an empirical comparison of stated and revealed preference value estimates. Ecol Econ. 2003;45:409-26.

12. Zelalem T, Aynalem $H$, Baker D, Girma. . Valuation of traits of indigenous sheep using hedonic pricing in central Ethiopia. Agric Food Economics. 2013;1(1):1-13.

13. Gutu Z, Haile A, Rischkowsky B, Mulema A, Kinati W, Kassie G. Evaluation of community-based sheep breeding programs in Ethiopia. Addis Ababa, ICARDA. 2015.

14. Aklilu N, Dawit A, Ayalineh B. Sheep market price determinants in the Central Rift Valley of Ethiopia. Int J Agric Econ Extd. 2013;1(1):010-6.

15. Andargachew K, Brokken R. Intra-annual sheep price patterns and factors underlying price variations in the central highlands of Ethiopia. Agric Econ. 1993;8(2):125-38.

16. Adugna T. Determinants of market prices of cattle in eastern Ethiopia. Contributed paper prepared for presentation at the International Association of Agricultural Economists Conference, Gold Coast, Australia. 12-18 Aug 2006

17. Beneberu T, Anteneh G, John A. Determinants of sheep prices in the highlands of northeastern Ethiopia: implication for sheep value chain development. Trop Anim Health Prod. 2011;43:1525-33.

18. Feven T. Price and performance analysis of indigenous sheep breed marketing in Menz districts of Ethiopia. A MSc thesis submitted to the Department of Agricultural Economics, School of Graduate Studies, Haramaya University, Ethiopia. 2009.

19. Getachew T, Teshale T, Ketema S. Study on common phenotypic traits for purchasing sheep and their association with price and purpose of purchase in four markets of East Showa zone. Ethiop Vet J. 2012;16(2):15-26.

20. Gezahegn A, Mohammad A, Hailemariom T, Elias M, Getahun K. Seasonal and inter-market differences in prices of small ruminants in Ethiopia. J Food Prod Mark. 2006;12(4):59-77.

21. Kenfo H, Mekasha $Y$, Tadesse $Y$. Assessment of consumer preference traits of indigenous sheep type and market channels in Bensa district, southern Ethiopia. East Afr Agric For J. 2019;83(2):149-62.

22. Teklewold H, Legese G, Alemu D, Negasa A. Determinants of livestock prices in Ethiopian pastoral livestock markets: implications for pastoral marketing strategies. In: Int Assoc Agric Econ Conf, Beijing. 16-22 Aug 2009. 
23. Mc Hugh N, Fahey AG, Evans RD, Berry DP. Factors associated with selling price of cattle at livestock marts. Animal. 2010;4(8):1378-89.

24. Rosen S. Hedonic prices and implicit markets: product differentiation in pure competition. J Polit Econ. 1974;82:34-55.

25. Bin O. Estimation of implicit prices in hedonic price models: flexible parametric versus additive nonparametric approach. Unpublished Doctoral Dissertation, University of Oregon State. 2000

26. Asresu Y, Yigezu A, Girma T, Tilaye T, et al. Identification of strategies to improve goat marketing in the lowlands of Ethiopia: a hedonic price analysis. Appl Econ. 2018;49:1-15.

27. Girma TK, Awudu A, Clemens W. Heteroscedastic hedonic price model for cattle in the rural markets of central Ethiopia. Appl Econ. 2011;43(24):3459-64.

28. Girma TK, Abdulai A, Wollny C. Valuing traits of indigenous cows in central Ethiopia. J Agric Econ. 2009;60(2):386-401.

29. Hysen B, Birgit F, Hajrip M, Roswitha B. Economic values for production traits for different sheep breeds in Kosovo. Ital J Anim Sci. 2015. https:// doi.org/10.4081/ijas.2015.3808.

30. Nadhem M, Derek B, James A, Edwin O, Julie O. Assessing sheep traders' preferences in Kenya: a best-worst experiment from Kajiado County. UMK Procedia. 2014;1:63-73.

31. Ouma E, Abdulai A, Drucker A. Measuring heterogeneous preferences for cattle traits amongst cattle keeping households in east Africa. Am J Agr Econ. 2007;89:1005-19.

32. Tarekegn K, Shitaye Y, Gafaro T. Does Bonga sheep producers' cooperative membership improve households' income in southern Ethiopia? Afr J Sci Technol Innov Dev. 2021;13(4):1-13. https://doi.org/10.1080/20421338. 2021.1945774.

33. Ahmad W, Tanvir A, Bashir A. Hedonic pricing of goat characteristics at the market level: the case of Pakistan. Int Food Agribus Manag Rev. 2019;22(4):483-97.

34. Barham BL, Troxel TR. Factors affecting the selling price of feeder cattle sold at Arkansas livestock auctions in 2005. J Anim Sci. 2007:85:3434-41.

35. Jabbar MA. Buyer preferences for sheep and goats in southern Nigeria: a hedonic price analysis. Agric Econ. 1998;18(1):21-30.

36. Kinkpé T, Diogo R, Kpadé C, Yabi J, Dossa L. The role of cattle attributes in buyers' choices in Benin. Afr J Agric Resour Econ. 2019;14(1):56-71.

37. Richards TJ, Jeffrey SR. Establishing indices of genetic merit using hedonic pricing: an application to dairy bulls in Alberta. Can J Agric Econ. 1996:44:251-64.

38. Williams O, Okike I, Spycher B. A hedonic analysis of cattle prices in the Central Corridor of west Africa: implications for production and marketing decisions. In: Int Assoc Agric Econ Conf. Gold Coast, Australia. 2006.

39. Srinivas T, Hassan A, Rischkowsky B, Tibbo M, Rizvi J, Naseri A. Hedonic analysis of price expectations of goat producers in Afghanistan: implications for production and marketing decisions. Agribusiness. 2013;29(2):133-46.

40. Parmenter CF, Pope JC. Quasi-experiments and hedonic property value methods. In: List JA, Price MK, editors. Handbook of Experimental Economics and Environment. Cheltenham: Edward Elgar Publishers; 2013.

41. Lawal A, Mohammed A, Musa S. Hedonic price analysis of characteristic influencing cattle prices in ngalda livestock markets in Yobe State. J Agric Sustain. 2016;9(1):43-57.

42. Costanigro M, McCluskey J, Mittelhammer R. Segmenting the wine market based on price: Hedonic regression when different prices mean different Products. J Agric Econ. 2007;58(3):454-66.

43. Cropper AL, Deck LB. McConnell KE On the choice of functional form for hedonic price functions. Rev Econ Stat. 1988;74(4):668-75.

44. Brown JE, Ethridge DE. Functional form model specification: an application to hedonic pricing. Agric Resour Econ Rev. 1995;24(2):166-73.

45. Ballco P, Gracia A. Do market prices correspond with consumer demands? Combining market valuation and consumer utility for extra virgin olive oil quality attributes in a traditional producing country. J Retail Consum Serv. 2020;53:1-11.

46. Box GE, Cox DR. An analysis of transformations. J R Stat Soc Ser B Methodol. 1964;26(2):211-52.

47. Ballco P, De-Magistris T. Valuation of nutritional and health claims for yoghurts in Spain: a hedonic price approach. Span J Agric Res. 2018;16(2):e0108. https://doi.org/10.5424/sjar/2018162-12130.

48. Cabrera ER, Arriaza M, Rodríguez-Entrena M. Is the extra virgin olive oil market facing a process of differentiation? A hedonic approach to disentangle the effect of quality attributes. Grasas Aceites. 2015;66(4):e105.

49. Vuong QH. Likelihood ratio tests for model selection and non-nested hypotheses. Econometrica. 1989;57(2):307-33.

50. Greene WH. Econometric analysis, 6th ed. Upper Saddle River: PrenticeHall; 2008.

51. Muhammad A. Using heteroscedasticity-consistent standard errors for the linear regression model with correlated regressors. Commun Stat Simul Comput. 2014;43(10):2353-73.

52. Gujarati D, Sangeetha N. Basic econometrics. New Delhi: Tata McGraw-Hill Publishing Company Limited; 2007.

53. White $\mathrm{H}$. A heteroskedasticity-consistent covariance matrix estimator and a direct test for heteroskedasticity. Econometrica. 1980;48(4):817-38.

54. Garson D. Testing statistical assumptions. In: Blue book series. North Carolina State University, Statistical Associates Publishing; 2012. https:// pdf4pro.com/view/testing-statistical-assumptions-2eac74.html.

55. Royston P. An extension of Shapiro and Wilks's W test for normality to large samples. Appl Stat. 1982;31:115-24.

56. Francisco C, Maria G. New heteroskedasticity-robust standard errors for the linear regression model. Braz J Probab Stat. 2014;28(1):83-95.

57. Long JS, Ervin L. Using heteroscedasticity—consistent standard errors in the linear regression model. Am Stat. 2000;54:217-24.

58. Verbeek M. A Guide to modern econometrics. 2nd ed. Hoboken: Wiley; 2004.

59. Hayes AF, Cai L. Using heteroskedasticity-consistent standard error estimators in OLS regression: an introduction and software implementation. Behav Res Methods. 2007:39(4):709-22.

60. Mackinnon JG, White H. Some heteroscedasticity consistent covariance matrix estimators with improved finite sample properties. J Econ. 1985;29:305-25.

61. Davidson R, Mackinnon J. Econometric theory and methods. Oxford: Oxford University Press; 1999.

62. Afzal M, Ahmad S, Baloch A, Ahmad Q. Seasonal price variation and price characteristics for small ruminants marketing in Balochistan. Pak J Agric Res. 2011;24:86-93.

63. Naanep ND, Velasco NB, Tayab CB, Dacayo FL, Jordan RC, Maltu JM, Villar EC. Traders' preferences for halal goat characteristics in selected markets in region xii, Philippines. Philipp J Vet Anim Sci. 2012;38(2):177-86.

64. Bimbo F, Bonnano A, Liu X, Viscechia R. Hedonic analysis of ultra-hightemperature treated milk prices in Italy. J Dairy Sci. 2015;99:1095-102.

65. Rodrigo RM, Mario LM, José MG. Market values for olive oil attributes in Chile: a hedonic price function. Br Food J. 2015;117(1):358-70.

66. Beneberu T, Amer J. Sheep price patterns and factors affecting price variations in the highland markets of North Shewa, Ethiopia. Jordan J Agric Sci. 2006:2(1):65-78.

67. Zewdie K, Teferi H. Determinants of market price of goats in case of Assayita market, Afar region, Ethiopia. Int J Adv Res Manag Soc Sci. 2017;6(5):177-90

68. Jabo M, Adamu M. Determinants of sheep price in Kaduna state, Nigeria. PAT. 2018;14(2):25-31.

\section{Publisher's Note}

Springer Nature remains neutral with regard to jurisdictional claims in published maps and institutional affiliations. 